\title{
A Parametric Study of Effect On Single Pile Integrity Due to An Adjacent Excavation Induced Stress Release in Soft Clay
}

\author{
Dildar Ali Mangnejo \\ Department of Civil Engineering \\ Mehran University of Engineering and \\ Technology \\ Sindh, Pakistan \\ dildarali72@gmail.com
}

\author{
Mukhtiar Ali Soomro \\ Department of Civil Engineering \\ Quaid-e-Awam University of \\ Engineering, Science \& Technology \\ Nawabshah, Pakistan \\ eng.soomro@gmail.com
}

\author{
Naeem Mangi \\ Department of Civil Engineering \\ Quaid-e-Awam University of \\ Engineering, Science \& Technology \\ Nawabshah, Pakistan \\ naeem08ce30@gmail.com
}

Imtiaz Ali Halepoto

Department of Computer Systems Engineering

Quaid-e-Awam University of Engineering, Science \& Technology

Nawabshah, Pakistan

halepoto@quest.edu.pk

\author{
Israr Ahmed Dahri \\ Department of Civil Engineering \\ Quaid-e-Awam University of Engineering, Science \& \\ Technology \\ Nawabshah, Pakistan \\ isrardahri55@gmail.com
}

\begin{abstract}
To gain new insights into single pile responses to adjacent excavations in soft ground, numerical parametric studies are carried out. An advanced hypoplastic (clay) constitutive model which takes account of small-strain stiffness is adopted. The effects of excavation depths (i.e. formation level) relative to pile were investigated by simulating the excavation near the pile shaft (i.e., $\left.H_{e} / L_{p}=0.67\right)$, next to $\left(H_{e} / L_{p}=1.00\right)$ and below the pile toe $\left(H_{e} / L_{p}=1.33\right)$. Among the three cases, the excavation in case of $H_{e} / L_{p}=1.33$ resulted in the largest pile settlement (i.e. $7.6 \% d_{p}$ ). On the other hand, the largest pile bending moment was induced in case of $H_{e} / L_{p}=0.67$.
\end{abstract}

Keywords-parametric study; different excavation depths; soft clay; single pile

\section{INTRODUCTION}

Due to the rate of population increment, it is desirable to construct multi-storey buildings in congested cities. It is well recognised that the favourable foundation for tall building is piling. Pile foundation not only carries vertical but also lateral loading. Besides this, underground constructions (i.e. basements and tunnels) are preferred to minimise traffic congestions. Hence, it is unavoidable to construct a basement or tunnel adjacent to pile foundations. It is well recognised that the capacity of a piled foundation depends on mobilised stresses in the ground while excavation is essentially a stress release process. Excavation may induce unfavourable ground deformations that can affect adjacent structures. Therefore, it is necessary to assess catastrophic effects on a piled foundation due to adjacent excavation. It is well recognised that superstructure load is transferred to surrounding soil through piled foundation. Consequently, high-stress regime is generated surrounding of the pile [1]. On the other hand, the excavation in the ground inevitably results to ground movement due to induced-stress release [2]. To cope with transportation problems in congested cities, underground transportation systems (involving metro tunnels, metro station excavations and parking basements) have been developed. These excavations are sometimes inevitable to be constructed adjacent to existing piled foundations. This condition leads to a big challenge for a geotechnical engineer to assess and protect the integrity of the piled foundation. Authors in $[3,4]$ reported case studies in granular soil and alluvium residual soil. In both reported case studies, the pile toe level was much deeper than the excavation level and authors reported only the lateral pile behaviour. This problem has also been investigated by means of centrifuge modelling [5] and pile group in soft kaolin clay [6]. They concluded that the distance between pile and diaphragm wall is an important parameter which plays a major role on induced bending moment in the pile. In the presence of initial applied load, soil surrounding the pile foundation experiences higher stress level before the commencement of adjacent excavation. The excavation induced stress release in the ground induced bending moment and settlement.

Authors in $[7,8]$ conducted centrifuge tests to investigate the effects of an un-propped excavation on the behavior of nearby single piles and pile groups in dry dense Toyoura sand. They found that the distance from the pile to the retaining wall and pile head conditions had a large influence on the induced pile bending moment and lateral deflection. Authors in [1] reported the results of three centrifuge tests carried out to study the effects of a multi-propped deep excavation in-flight on the 
behavior of single piles in dry Toyoura sand. Piles were laterally restrained in terms of rotation and deflection right at or above ground surface in three different tests. It was concluded that lateral restraints imposed on the pile head have a significant influence on induced pile bending moment. Induced bending moment due to excavation can exceed the pile bending capacity. Authors in [9] investigated the lateral responses of a single pile to an adjacent excavation. They performed two staged analysis, considering plane strain conditions and linear elastic soil model. Similar work was conducted in [10] using finite element method. In both these studies lateral response of single pile was investigated. The settlement behaviour of pile and development of excess pore water pressure and consolidation settlement were not investigated. In [11] an analytical method was proposed in order to investigate the reduction of capacity and increase in settlement of a nearby pile during excavation. It was reported that pile settlement due to excavation depends on the percentages of end bearing and shaft friction of the pile, the soil movement pattern and the distribution of the maximum shaft friction with depth. However, shaft resistance in these methods is calculated on the assumption that horizontal stress acting on the piles does not change during excavation. This assumption may not be valid and the pile settlement may be underestimated using the preceding methods, leading to a non-conservative prediction. Most of the previous studies focused on the lateral response of the piled foundation to excavation. In addition, different formation levels with respect to pile have not been understood. The effects of excavation on the behaviour of piles (i.e. induced settlement and axial forces along the pile length) were rarely reported. The main objective of this parametric study is to understand the mechanism of the effects of excavation depth systems of different formation level on a loaded single floating pile. A 3D finite element analysis was conducted to investigate the above mentioned problem. Settlement and load transfer mechanism were reported and discussed.

\section{THREE-DIMENSIONAL COUPLED CONSOLIDATION ANALYSIS}

A 3D finite element analysis (i.e. coupled consolidation parametric study) was conducted to investigate the problem. In this parametric study, final excavation depths $\left(H_{e}\right)$ were taken as $12 \mathrm{~m}, 18 \mathrm{~m}$ and $24 \mathrm{~m}$. The effects of these excavations were investigated on a loaded single pile of length embedded length $\left(L_{p}\right)$ of $18 \mathrm{~m}$ with diameter $\left(d_{p}\right)$ of $0.8 \mathrm{~m}$. The pile can sustain maximum bending moment of $800 \mathrm{kNm}$. Figure 1(a) shows the elevation view of the configuration of numerical simulation of a typical case of $H_{e} / L_{p}=0.67$. The clear distance between diaphragm wall and the pile is $3.0 \mathrm{~m}$. The excavation was supported by a $0.6 \mathrm{~m}$ thick diaphragm wall. The ratio of wall penetration depth to excavation depth is typically $0.5-2$ [12] and a value of 0.5 is adopted in this study. The props are used to support the diaphragm wall with a vertical spacing of $3 \mathrm{~m}$. The props are modelled as soft with axial rigidity of $81 \times 10^{3} \mathrm{kNm}$ [12]. Horizontal spacing of props is $10 \mathrm{~m}$. Figure 1(b) shows the configuration (plan view) of the numerical model in case of $H_{e} / L_{p}=0.67$. The length of the excavation is $12 \mathrm{~m}$. As excavation possesses symmetry, therefore, half excavation (with length $6 \mathrm{~m}$ ) was modeled. In addition to these simulations, a pile load test $(L)$ is proposed to be conducted numerically in "greenfield" conditions (i.e. no excavation) to obtain the ultimate capacity of the pile in silty clay. Based on this, the working load will be obtained with a factor of safety of 3.0. The obtained working load will be applied to the pile in the parametric analysis simulating excavation. Table I summarises the numerical simulations conducted in this study.

\section{A. Constitutive Model and Model Parameters Used in Finite Element Analysis}

The basic hypoplastic model was developed to capture the non-linear behavior (upon monotonic loading at medium to large-strain levels) of granular materials [19-20]. The basic model consists of five parameters $\left(N, \lambda^{*}, \kappa^{*}, \varphi_{c}\right.$ and $\left.r\right)$. The parameters $\mathrm{N}$ and $\lambda^{*}$ define the position and the slope of the isotropic normal compression line in the $\ln (1+e)$ versus $\ln p$ ' plane [10], $e$ is the void ratio and $p$ ' is the mean effective stress, $\kappa^{*}$ defines the slope of the isotropic unloading line in the same plane, $\varphi_{c}$ is the critical state friction angle, and $r$ controls the large strain shear modulus.

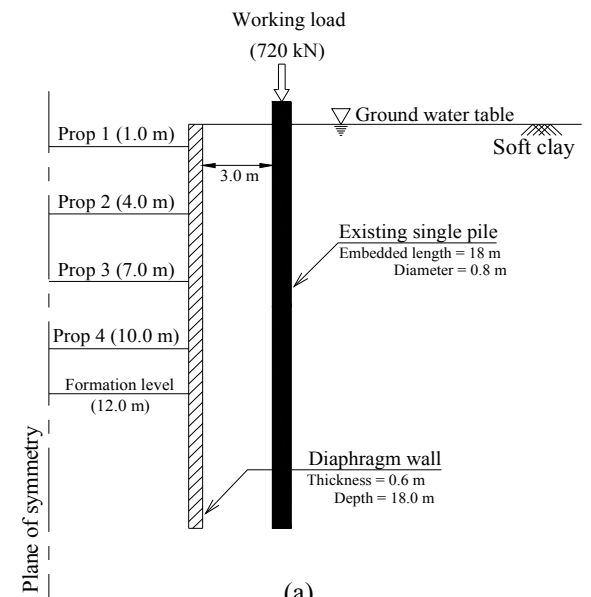

(a)

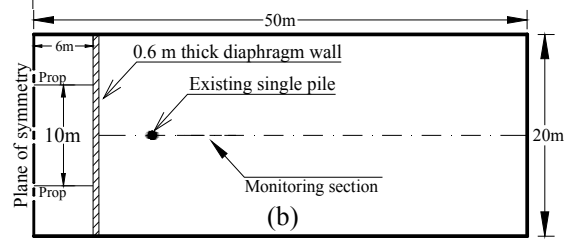

Fig. 1. Configuration of a numerical model in the case of $H_{e} / L_{p}=0.67$. (a) Elevation view, (b) Plan view

TABLE I. NUMERICAL SIMULATION PLAN

\begin{tabular}{|c|c|c|c|}
\hline Simulation ID & $\begin{array}{c}\text { Excavation } \\
\text { depth (m) }\end{array}$ & $\begin{array}{c}\text { Diaphragm } \\
\text { wall depth (m) }\end{array}$ & Remark \\
\hline$L$ & N/A & N/A & Pile load test \\
\hline$H_{e} / L_{p}=0.67$ & 12.0 & 18.0 & $\begin{array}{c}\text { Formation level near } \\
\text { pile shaft }\end{array}$ \\
\hline$H_{e} / L_{p}=1.00$ & 18.0 & 24.0 & $\begin{array}{c}\text { Formation level next } \\
\text { to pile toe }\end{array}$ \\
\hline$H_{e} / L_{p}=1.33$ & 24.0 & 36.0 & $\begin{array}{c}\text { Formation level } \\
\text { below pile toe }\end{array}$ \\
\hline
\end{tabular}


To account for the strain-dependency and path-dependency of the soil stiffness (at small strains), authors in [13] further improved the basic hypoplastic model by incorporating the concept of intergranular strain. The intergranular strain concept requires five additional parameters $\left(R, \beta_{r}, \chi, m_{T}\right.$, and $\left.m_{R}\right): \mathrm{R}$ controls the size of the elastic range, $\beta_{r}$ and $\chi$ control the rate of stiffness degradation while $m_{T}$ and $m_{R}$ control the initial shear modulus upon $180^{\circ}$ and $90^{\circ}$ strain path reversal, respectively. In this hypothesised study, the parameters from [14] for silty clay were adopted and are summarised in Table II. The coefficient of lateral earth pressure at rest, $K_{o}$ is estimated by (1) [15]:

$$
K_{0}=\left(1-\sin \varphi^{\prime}\right)(O C R)^{\sin \varphi^{\prime} \cdot \cdot}
$$

TABLE II. MODEL PARAMETERS OF SILTY CLAY ADOPTED FROM [14]

\begin{tabular}{|c|c|}
\hline Description & Value \\
\hline Effective angle of shearing resistance at critical state: $\phi^{\prime}$ & 330 \\
\hline $\begin{array}{l}\text { Parameter controlling the slope of the isotropic normal } \\
\text { compression line in the } \ln (1+\mathrm{e}) \text { versus } \ln p \text { plane, } \lambda^{*}\end{array}$ & 0.103 \\
\hline $\begin{array}{l}\text { Parameter controlling the slope of the isotropic normal } \\
\text { compression line in the } \ln (1+\mathrm{e}) \text { versus } \ln p \text { plane, } \kappa^{*}\end{array}$ & 0.015 \\
\hline $\begin{array}{l}\text { Parameter controlling the position of the isotropic normal } \\
\text { compression line in the } \ln (1+\mathrm{e}) \text { versus } \ln \text { p plane, } N\end{array}$ & 1.31 \\
\hline $\begin{array}{l}\text { Parameter controlling the shear stiffness at medium- to large- strain } \\
\text { levels, } r\end{array}$ & 0.3 \\
\hline $\begin{array}{l}\text { Parameter controlling initial shear modulus upon } 180^{\circ} \text { strain path } \\
\text { reversal, } m_{R}\end{array}$ & 12 \\
\hline $\begin{array}{l}\text { Parameter controlling initial shear modulus upon } 90^{\circ} \text { strain path } \\
\text { reversal, } m_{T}\end{array}$ & 12 \\
\hline Size of elastic range, $R$ & $2 \times 10-5$ \\
\hline $\begin{array}{l}\text { Parameter controlling the rate of degradation of the stiffness with } \\
\text { strain, } \beta_{r}\end{array}$ & 0.09 \\
\hline Parameter controlling degradation rate of stiffness with strain, $\chi$ & 0.7 \\
\hline Initial void ratio, $e$ & 0.7 \\
\hline Dry density $\left(\mathrm{kN} / \mathrm{m}^{3}\right)$ & 1615 \\
\hline Coefficient of permeability, $k(\mathrm{~m} / \mathrm{s})$ & $1 \times 10-9$ \\
\hline
\end{tabular}

\section{B. Finite Element Mesh and Boundary Condition}

Figure 2 shows a finite element mesh used in the case of $H_{e} / L_{p}=0.67$ with size of $50 \mathrm{~m} \times 20 \mathrm{~m} \times 40 \mathrm{~m}$. Solid elements were used to model soil, pile and the diaphragm wall. The props were modeled by using truss elements. To restrain the horizontal and vertical movement, roller supports were applied. The base of the mesh was restrained in every direction by applying pin supports on it. The ground water table level was taken at ground surface. At geostatic state, pore pressure distribution was taken as hydrostatic. The top of the mesh was considered drainage boundary. The frictional interface was taken between pile and soil and wall and soil. The Coulomb law for capturing frictional behavior was used in the interface. The Coulomb's frictional law parameters $\mu$ and limiting displacement was taken as $0.35 \mathrm{~mm}$ and $5 \mathrm{~mm}$, respectively [16].

Excavation was carried out by deactivating soil elements within the zone of excavation in each analysis. Activation of truss elements procedure was adopted for prop installation on the wall. The concrete pile, the diaphragm wall and the props were taken as elastic material with $E=35 \mathrm{GPa}$ and $v=0.25$. These parameters are given in Table III.
TABLE III. CONCRETE PARAMETERS

\begin{tabular}{|c|c|}
\hline Description & Parameter \\
\hline Young's Modulus, $E$ & $35 \mathrm{GPa}$ \\
\hline Poisson's ratio, $v$ & 0.3 \\
\hline Density, $\rho$ & $2400 \mathrm{~kg} / \mathrm{m}^{3}$ \\
\hline
\end{tabular}

\section{Procedure of Numerical Modeling}

The following is the procedure adopted for numerical modeling for a typical case $H_{e} / L_{p}=0.67$.

- Generate geostatic stresses under $K_{o}$ condition and apply the boundary conditions as discussed above.

- Activate pile elements with application of working load as discussed above.

- Activate the brick elements representing the diaphragm wall.

- Staged multi-propped excavation is simulated as described in Section II. After excavating to $3 \mathrm{~m}$ depth, the first level of props is installed at $1 \mathrm{~m}$ below the ground surface.

- Same steps were taken for the remaining stages of excavation and props installation.

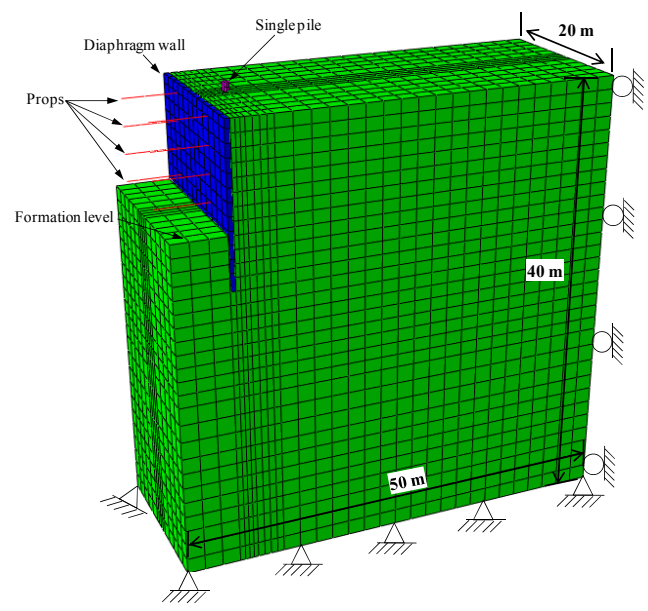

Fig. 2. The mesh and boundary conditions in the case where $H_{e} / L_{p}=0.67$

\section{INTERPRETATION OF COMPUTED RESULTS}

\section{A. Determination of Working Load for the Pile}

The objective of this parameter is to investigate the loaded single pile responses to adjacent excavations with different formation level relative to the pile length in soft clay. A numerical pile load test was conducted to compute the pile load carrying capacity. Load of $3 \mathrm{MN}$ (with increment of $0.27 \mathrm{MN}$ ) was applied on the pile over a period of 24 hours. Figure 3 shows the computed load-settlement curve. A displacementbased failure criterion (see [17]) was used to obtain the load carrying capacity of the pile.

$$
\delta_{p h, \text { max }} \cong 0.045 d_{p}+\frac{1}{2} \frac{P_{h} L_{p}}{A_{p} E_{p}}
$$


Based on this, the obtained load carrying capacity of the pile was $2.15 \mathrm{MN}$. The working load was found to be $0.72 \mathrm{MN}$ with a factor of safety (FOS) equal to 3 . The pile settled at $5.12 \mathrm{~mm}\left(0.64 \% d_{p}\right)$ due to application of the working load.

\section{B. Excavation-Induced Pile Settlement}

Figure 4 illustrates the normalised incremental settlement of the pile $\left(S_{p} / d_{p}\right)$ with different excavation depths in all three cases (i.e. $H_{e} / L_{p}=0.67, H_{e} / L_{p}=1.00$ and $H_{e} / L_{p}=1.33$ ). Excavation depths are indicated by $h$. The measured centrifuge modeling [1] single pile settlement due to excavation in dry sand is also included in the figure. Excavation depth was $8 \mathrm{~m}$ (in prototype scale) in the centrifuge test. It can be seen from the figure that bi-linear increment in $S_{p}$ was observed with increasing excavation depth in each case. The $S_{p}$ increased linearly with excavation depth, however, the rate of induced settlement increased during the last two excavation stages (i.e. 6-12m, 12$18 \mathrm{~m}$ and $18-24 \mathrm{~m}$ for of $H_{e} / L_{p}=0.67, H_{e} / L_{p}=1.00$ and $H_{e} / L_{p}=1.33$ respectively). This is because of the degradation of clay stiffness due to excavation-induced stress release and shear strain surrounding the pile. Similar characteristics of excavation-induced settlement of single pile were observed from the centrifuge test reported in [1]. However, because of higher stiffness of sand, induced settlement of single pile in sand was smaller than that in clay. By comparing induced settlement of the pile for $H_{e} / L_{p}=0.67$ and $H_{e} / L_{p}=1.00$, it is observed that the $S_{p}$ during the last two excavation stages in the former case is larger than that during similar excavation stages in the latter case. To be more specific, with same stress release due to excavation stages $(9-12 \mathrm{~m})$, larger settlement was induced in the case of $H_{e} / L_{p}=0.67$ than that in the case of $H_{e} / L_{p}=1.00$.

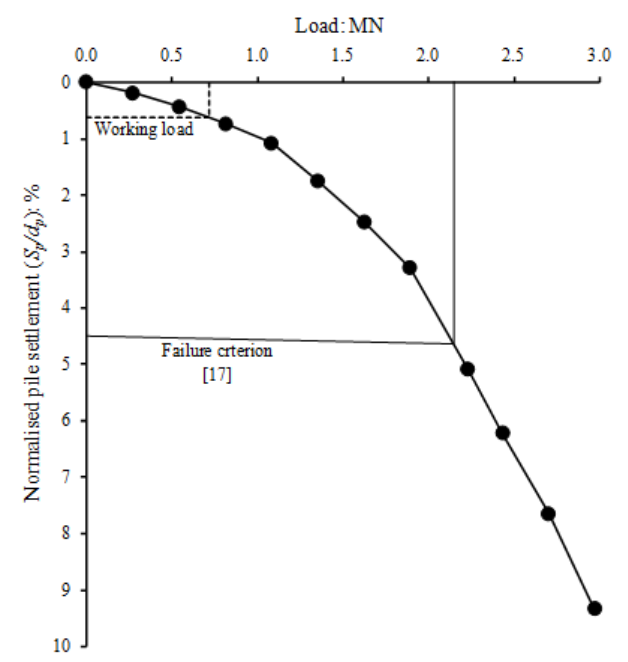

Fig. 3. Load settlement curve obtained from simulation $L$.

The additional amounts of induced-settlement at excavation depths of $9 \mathrm{~m}$ and $12 \mathrm{~m}$ are $1.55 d_{p} \%$ and $2.1 d_{p} \%$, respectively. Similarly, the $S_{p}$ induced during excavation stages (12-18m) for $H_{e} / L_{p}=1.00$ is larger than the $S_{p}$ induced for $H_{e} / L_{p}=1.33$ because of the different embedded depths of the wall in each case. This revealed that the induced-settlement highly depends on the wall stiffness. Among the three cases discussed, the largest and smallest settlement induced in the pile are for $H_{e} / L_{p}=1.33$ and $H_{e} / L_{p}=0.67$ respectively. This settlement behavior can be attributed to two reasons: The pile is subjected to higher stress release due to excavation in case of $H_{e} / L_{p}=1.33$ than that due to excavation in case of $H_{e} / L_{p}=0.67$, and the entire pile is located within the zone of excavation-induced displacement in case of $H_{e} / L_{p}=1.33$. The single pile experienced total settlements (due to working-load and excavation) of $39,51.5$ and $66 \mathrm{~mm}$ (i.e. $4.9,6.4$ and $8.3 \%$ of pile diameter) for $H_{e} / L_{p}=0.67, H_{e} / L_{p}=1.00$ and $H_{e} / L_{p}=1.33$ respectively.

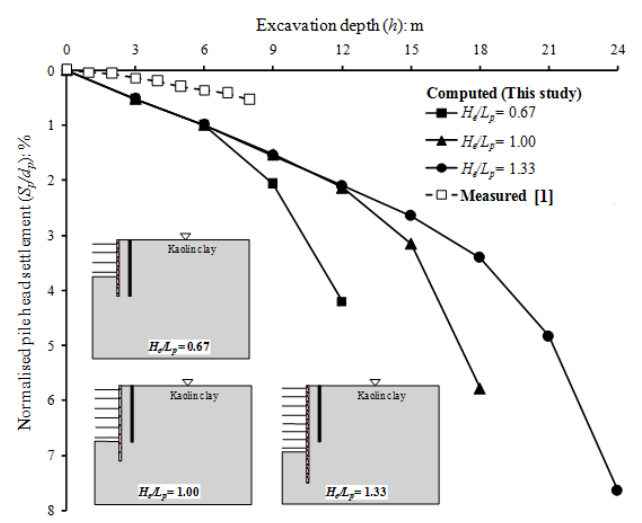

Fig. 4. Normalised pile head settlement during excavation

\section{Excavation-Induced Bending Moment in the Pile}

Figure 5 illustrates the bending moment profile in pile on completion of excavation for all three cases. The excavationinduced bending moment profile measured in centrifuge test (excavation depth $1.2 \mathrm{~m}$ ) in [5] is also included for comparison with induced bending moment in case of $H_{e} / L_{p}=0.67$. A positive bending moment value indicates that the compressive stresses are induced along the face of the shaft towards the excavation. The induced-bending moment is taken as positive if compressive stress was induced along the pile shaft facing the excavation. No bending moment was computed at the pile head because the pile heads were not constraint in each case. On completion of excavation, with formation level at middepth of the pile (i.e. $H_{e} / L_{p}=0.67$ ), positive bending moments were induced along the entire pile. The bending moment increased linearly along the pile length with the maximum magnitude of $127 \mathrm{kNm}$ at $Z / L_{p}=0.8$ (i.e. above formation level). This is because the pile was subjected to lateral soil displacements towards the excavation due to stress release. As pile displaced lateral with soil as rigid body, no bending moment was induced at the pile toe.

The measured bending moment profile in centrifuge in [5] shows the similar trend with the computed bending moment in this study. The maximum bending moment was also reported to be above formation level. This agreement between computed and measured results gives confidence that finite element analysis can predict accurately the behavior of a single pile due to excavation-induced stress release. In contrast to induced bending moment in case of $H_{e} / L_{p}=0.67$, negative bending moment profile was established on completion of excavation 
for $H_{e} / L_{p}=1.00$ and $H_{e} / L_{p}=1.33$. The reason for this bending profile can be attributed to the embedded depth of the wall which makes soil displacement milder than that of $H_{e} / L_{p}=0.67$. The maximum bending moment of $42 \mathrm{kNm}$ and $13 \mathrm{kNm}$ at $Z / L_{p}=0.7$ were induced in the pile in case of $H_{e} / L_{p}=1.00$ and 1.33 , respectively. It can be seen that the maximum induced bending moment at the excavation end all the three cases is much less than the pile bending moment capacity $(800 \mathrm{kNm})$. Therefore, the most critical issue to be considered in the excavation-soil-pile problem is the relatively large settlement and the lateral pile displacement.

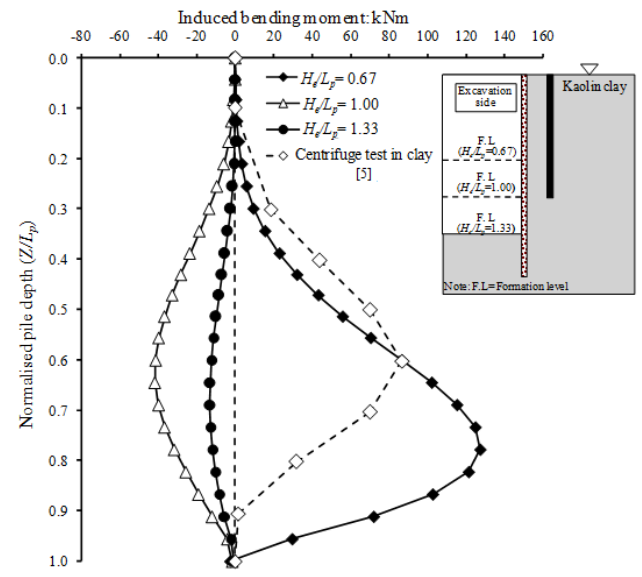

Fig. 5. Induced bending moment due to excavation

\section{CONCLUSIONS}

- Because of the different embedded depth of the wall in each of the three cases, the induced settlement $\left(S_{p}\right)$, lateral displacement and bending moment in the pile at the same stage of the excavation were different.

- By comparing the induced settlement of the pile for $H_{e} / L_{p}=0.67$ and $H_{e} / L_{p}=1.00$, it is observed that the $S_{p}$ during last two excavation stages in the former case is larger than that of the latter case. Similarly, the $S_{p}$ induced during excavation stages $(12-18 \mathrm{~m})$ for $H_{e} / L_{p}=1.00$ is higher than for $H_{e} / L_{p}=1.33$. Final induced settlement (due to working-load and on completion of the excavation respectively) of $39,51.5$ and $66 \mathrm{~mm}(4.9,6.4$ and $8.3 \%$ of pile diameter) was computed for the cases $H_{e} / L_{p}=0.67$, $H_{e} / L_{p}=1.00$ and $H_{e} / L_{p}=1.33$, respectively.

- Due to excavation induced stress release, the bending moment was induced along the pile length. At the end of excavation in each case, the maximum induced bending moment in all cases was much less than the pile bending moment capacity. Therefore, the most critical issue to be considered in excavation-soil-pile in soft Kaolin clay problem is the relatively large settlement and lateral displacement of the pile. This conclusion may not be applicable to scenarios in which the ground conditions or the stiffness of the excavation system are different from those adopted in this study.

\section{REFERENCES}

[1] C. W. W. Ng, J. Wei, H. G. Poulos, H. Liu, "Effects of Multipropped Excavation on an Adjacent Floating Pile", Journal of Geotechnical and Geoenvironmental Engineering, Vol. 143, No. 7, pp. 04017021-1 04017021-14, 2017

[2] M. Korff, R. J. Mair, F. A. F. Van Tol, "Pile-Soil Interaction and Settlement Effects Induced by Deep Excavations", Journal of Geotechnical and Geoenvironmental Engineering, Vol. 142, No. 8, pp. 04016034-1 - 04016034-14, 2016

[3] R. J. Finno, S. A. Lawrence, N. F. Allawh, I. S. Harahap, "Analysis of performance of pile groups adjacent to deep excavation", Journal of Geotechnical and Geoenvironmental Engineering, Vol. 117, No. 6, pp. 934-955, 1991

[4] A. Goh, K. Wong, C. Teh, D. Wen, "Pile response adjacent to braced excavation", Journal of Geotechnical and Geoenvironmental Engineering, Vol. 129, No. 4, pp. 383-386, 2003

[5] D. Ong, C. F. Leung, Y. Chow, "Pile behavior due to excavationinduced soil movement in clay. I: Stable wall", Journal of Geotechnical and Geoenvironmental Engineering, Vol. 132, No. 1, pp. 36-44, 2006

[6] D. Ong, C. F. Leung, Y. Chow, "Behavior of pile groups subject to excavation-induced soil movement in very soft clay", Journal of Geotechnical and Geoenvironmental Engineering, Vol. 135, No. 10, pp. 1462-1474, 2009

[7] C. F. Leung, Y. Chow, R. F. Shen, "Behavior of pile subject to excavation-induced soil movement", Journal of Geotechnical and Geoenvironmental Engineering, Vol. 126, No. 11, pp. 947-954, 2000

[8] C. F. Leung, J. K. Lim, R. F. Shen, Y. K. Chow, "Behavior of pile groups subject to excavation-induced soil movement", Journal of Geotechnical and Geoenvironmental Engineering, Vol. 129, No. 1, pp. 58-65, 2003

[9] H. G. Poulos, L. Chen, "Pile response due to excavation induced lateral soil movement", Journal of Geotechnical and Geoenvironmental Engineering, Vol. 123, No. 2, pp. 94-99, 1997

[10] R. Butterfield, "A natural compression law for soils", Geotechnique, Vol. 29, No. 4, pp. 469-480, 1979

[11] B. C. B. Hsiung, "A case study on the behaviour of a deep excavation in sand", Computer and Geotechnics, Vol. 36, No. 4, pp. 665-675, 2009

[12] D. Liyanapathirana, R. Nishanthan, "Influence of deep excavation induced ground movements on adjacent piles", Tunnelling and Underground Space Technology, Vol. 52, pp. 168-181, 2016

[13] A. Niemunis, I. Herle, "Hypoplastic model for cohesionless soils with elastic strain range", Mechanics of Cohesive-Frictional Materials, Vol. 2, No. 4, pp. 279-299, 1997

[14] D. Masin, J. Bohac, P. Tuma, "Modelling of a deep excavation in a silty clay", in: Proceedings of the 15th European Conference on Soil Mechanics and Geotechnical Engineering, Athens, Greece, Vol. 3, pp. 1509-1514, 2011

[15] P. Mayne, F. Kulhawy, "K0-OCR relationships in soils", Journal of Geotechnical Engineering, Vol. 108, No. 6, pp. 851-872, 1982

[16] N. Loganathan, H. G. Poulos, D. P. Stewart, "Centrifuge model testing of tunnelling-induced ground and pile deformations", Geotechnique, Vol. 50, No. 3, pp. 283-294, 2000

[17] C. W. W. Ng, T. L. Y. Yau, J. H. M. Li, W. H. Tang, "New failure load criterion for large diameter bored piles in weathered geomaterials", Journal of Geotechnical and Geoenvironmental Engineering, Vol. 127, No. 6, pp. 488-498, 2001 